\title{
LA ÉTICA DIFERENCIAL DE ROSI BRAIDOTTI
}

\author{
Brais GonZÁlez ARribas ${ }^{\mathrm{I}}$ \\ UNED, Madrid \\ http://dx.doi.org/10.15304/ag.37.2.4364
}

\section{Resumen}

En este artículo se analiza la ética de la diferencia elaborada por Rosi Braidotti, así como la concepción de la subjetividad nómade y posthumana que la sostiene. La propuesta de Braidotti, que se define por una decidida apuesta por la positividad y la inmanencia, nos permite articular una alternativa consistente y viable a la ética liberal e individualista, que tiene su raíz en el humanismo tradicional, intentando asimismo reparar los peores peligros que la afectan: la legitimación y reproducción de una violencia que impide y bloquea el desenvolvimiento de la alteridad que no se adecúa a la idea de ser humano dominante.

Palabras clave: ética, diferencia, alteridad, positividad, Braidotti.

\section{Abstract}

The ethics of difference developed by Rosi Braidotti is analysed in this article as well as the conception of nomadic and posthuman subjectivity that supports it. Braidotti's proposal, that it is defined as a firm intent for positivity and immanence, allows us to articulate a coherent and viable alternative to liberal and individualistic ethics, which has its root in traditional humanism, trying also to repair the worst dangers that affect it: the legitimation and reproduction of a violence that prevents and blocks the development of the alterity that does not fit in with the dominant idea of human being.

Keywords: ethics, difference, alterity, positivity, Braidotti.

Recibido: 17/10/2017. Aceptado: 20/12/2017.

${ }^{1}$ Doctor en Filosofía (UNED). Investigador de la Cátedra de Hermenéutica crítica, Hercritia, UNED, Madrid. 


\section{Una ética de la diferencia}

Uno de los ejemplos más representativos de la ética diferencial positiva nos lo proporciona la filósofa italo-australiana Rosi Braidotti, quien a lo largo de su obra, incide tanto en el carácter positivo de la noción de diferencia, como en las consecuencias que ello acarrea en el orden práctico. Al enfatizar la positividad de la diferencia, Braidotti pretende rescatarla de la mala reputación que tenía en el pensamiento tradicional, donde enmarcada en el contexto de la ontología sustancialista, de la concepción lineal del tiempo y del humanismo clásico, fue empleada como la categoría que hizo posible la distinción entre órdenes jerárquicos de ser, clasificando como más avanzados o más próximos al ideal civilizatorio a la cultura occidental y al prototipo de ser humano impulsado en esta: el Hombre blanco, heterosexual, cristiano y propietario, por sintetizarlo en sus atributos más representativos. En el marco de la filosofía moderna, y dada la noción de diferencia, se han clasificado modalidades distintas de ser, de vivir o de pensar como más o menos perfeccionadas, o simplemente como "mejores" o "peores", en base a su proximidad o adecuación con la realización de una cierta Idea - la Razón, la Salvación, la Felicidad, la Libertad o la Igualdad-, la cual ha ejercido tradicionalmente de criterio o referente último de valoración.

En el contexto de la cultura tradicional, la diferencia ha servido como un elemento de contraste o comparación teñido de fuertes repercusiones prácticas, siendo utilizada como un mecanismo de legitimación para la discriminación, segregación y marginación de ciertos grupos sociales en base a la identidad que les fue asignada como propia. Dicho de otra manera, en el contexto del pensamiento históricamente dominante —el de la metafísica de la presencia-, la categoría de diferencia ha dado lugar a una distribución desigual de (los individuos que componen) la sociedad, donde una idea muy específica del ser humano se ha impuesto sobre otras, funcionando como un ideal o canon regulativo con el que contrastarse y al que aspirar. En tal marco, la diferencia pierde gran parte de la riqueza de su significación, al ser entregada a una estructura de pensamiento en la que prima la unidad o la homogeneización de las subjetividades, ya que aquellas que no responden o que se distinguen de la hegemónica, bien son segregadas o situadas en los márgenes, cuando no son reprimidas y perseguidas, bien se les adjudica una posición de subordinación respecto de aquella, conformando un sistema social marcadamente jerárquico y estratificado. 
A juicio de Braidotti (2005: 17), este modo de presentar la diferencia socava su potencial subversivo, ya que, por una parte, la convierte en un concepto moralmente rechazable que está al servicio de un pensamiento autoritario y jerarquizante y, por otra - lo cual es incluso más graveconfunde el alcance y el significado del pensamiento de la diferencia, ya que este precisamente se opone a la filosofía que legitima la existencia de jerarquías, las cuales sólo pueden ser justificadas si se plantea la existencia de un modelo o ideal concreto de ser humano, siendo este, como decíamos, el que se corresponde con el Hombre blanco-occidental heterosexual, cristiano y propietario. Quien no responda a tal canon simplemente debe ser despreciado y relegado política y socialmente.

Pues bien, Braidotti pretende invertir los términos de tal ecuación recuperando la significación positiva de la diferencia ${ }^{2}$, y lo hace partiendo de la herencia recibida por el posestructuralismo de Irigaray, Foucault, Lyotard o Deleuze, siendo este último un referente teórico esencial del que Braidotti hace uso reiteradamente para la construcción de su propio pensamiento. Según Braidotti, en el contexto contemporáneo, el de la crisis de la modernidad y de la noción de sujeto defendida en ella (una entidad autoconsciente que coincide con su yo racional), dejan de valer las perspectivas universalizantes de la humanidad, por eso el canon citado líneas arriba deja de representar el modelo de ser humano al que aspirar. Una vez que se impugna la validez del criterio de referencia que identifica el modo correcto de ser ser humano, se abre la puerta a todos aquellos sujetos que fueron definidos como diferentes respecto de aquel. En tal sentido, el pensamiento de la diferencia adquiere ya una cierta dimensión ética: su primer y más importante deber consiste en articular las estrategias simbólicas que permitan que las minorías marginadas dejen de ser el "otro" como el primer paso necesario cara a obtener una dignidad propia que, en último término, debe hacerles acreedoras de retomar la voz que les había sido arrebatada para empezar a construir en igualdad de condiciones tanto una subjetividad como un entorno habitables. ${ }^{3}$ En ese sentido, el intento por potenciar la diferencia dándole

${ }^{2}$ El problema de la diferencia es uno de los más discutidos y analizados a lo largo del pensamiento de la segunda parte del siglo XX, por lo menos desde que Heidegger situara la cuestión de la diferencia ontológica en un plano central para el estudio y la comprensión de la historia de la filosofía occidental. La hermenéutica ontológica, el estructuralismo o el posestructuralismo, han abordado desde distintos puntos de vista la citada cuestión, y es siguiendo la senda abierta por este último, sobre todo en continuidad con la obra de Gilles Deleuze, donde hay que situar la obra de Braidotti.

${ }^{3}$ Sostiene literalmente Braidotti, "refutando esta representación inapropiada del sujeto, el pensamiento crítico moderno presta su voz y autoriza a hablar a los sujetos pertenecientes 
voz a los "otros" silenciados, se convierte en uno de los grandes objetivos que vertebran la obra de Braidotti, lo cual, en la práctica, supone promover la elaboración de nuevas representaciones y valores culturales que permitan la proliferación no ya sólo de diferentes modos de vida sino de distintas subjetividades alternativas a la hegemónica.

El carácter positivo de la diferencia, en la obra de la filósofa italo-australiana, remite por tanto a la potenciación de la heterogeneidad, al acontecimiento ontológico que da pie a la apertura de modos no acaecidos de ser. Dada la diferencia, la existencia prolifera, se multiplica, deviene, fluye. La potencia busca expandirse intensivamente aprovechando la energía vital para dejar aparecer formas no sidas de ser. De ahí que haya una relación explícita, en Braidotti, entre ontología y ética.

\section{El debate en torno a la subjetividad}

Como se sugería en el apartado anterior, la aplicación de una ética de la diferencia requiere como paso previo el análisis del tipo de subjetividad predominante, pues en la medida en que un determinado modo de interpretarla se convierte en hegemónico, se vuelven a su vez fuertes las estrategias teóricas que bloquean la aparición de modalidades alternativas a la misma, al ser entendidas como versiones desviadas, deficitarias o monstruosas respecto de la subjetividad normal. Ahora bien, ¿qué constituye una subjetividad normal? ¿Hasta qué punto la concepción dominante de ser humano ha sobrestimado ciertos atributos y negado otros? ¿En qué medida ello ha contribuido a oprimir y subyugar a extensas capas de población?

Con el objetivo de replantearse este tipo de cuestiones y para dar cabida a modos de subjetivación rechazados tradicionalmente, Braidotti, en la línea de otras pensadoras feministas de referencia como Luce Irigaray o Judith Butler, propone deconstruir la idea de subjetividad dominante, lo cual - y a la vez- debe permitir iniciar la recuperación de aquellas otras que en su diferencia fueron consideradas anormales, anómalas, defectuosas y, por ello, rechazables. Uno de los rasgos positivos que la definen es, en consecuencia, la atención por la alteridad, su escucha y cuidado, lo que implica no sólo la reflexión sobre las diversas posibilidades (de ser) que se abren una vez que la idea centro que se adopta para establecer qué y cómo

a minorías simbólicas, aquello que fueron definidos como diferentes. Entre esas diferencias las principales son el sexo y la raza” (2004: 19). 
debe ser un ser humano "normal” queda en suspenso, sino también la reparación de aquellas otras que fueron sistemáticamente negadas, apartadas y marginadas al no concordar con esta.

Un primer paso cara a la recuperación de la alteridad, consiste en idear estrategias que permitan reconsiderar la validez de la idea de subjetividad dominante mostrando, a la vez, la riqueza de lo que se oculta cuando solo una se impone. ${ }^{4}$ Si en último término se pretende aumentar la diversidad de la existencia y amplificar la intensidad de ser dando lugar a la proliferación de la diferencia, una de las maniobras más útiles para conseguirlo consiste en potenciar la conformación de singularidades, de identidades complejas y múltiples que no respondan a la idea mayoritaria de la misma. Se trata entonces de defender la heterogeneidad de lo singular más allá del dominio de la idea canónica de Hombre, de la mentalidad humanista y antropocéntrica que la impulsa y mantiene. La diferencia se encuentra cabalmente en la defensa de los grupos sociales sometidos - la mujer, el colonizado (el salvaje), el homosexual o el pobre-, pero también en la atención por la pluralidad individual —el derecho a ser una entidad dividida o fragmentada: múltiple y contradictoria- y por la aceptación de que el ser humano es un animal más que forma parte del entorno natural, con el que debe mantener la mayor de las responsabilidades. La promoción de la singularidad en gran medida depende de la resistencia a los procesos de normalización que inculcan una manera específica de ser, de pensar o de comportarse, a la vez que moldean y definen los cuerpos. Por ello, el rechazo de la identidad asignada, o al menos su puesta en discusión, requiere la realización de un ejercicio de autodisolución que examine los principios y criterios sobre los que se ha edificado el modo adecuado e idóneo de ser ser humano, en el contexto

${ }^{4}$ En realidad, Braidotti aborda uno de los temas más recurrentes del pensamiento contemporáneo en Occidente, ya que gran parte de la filosofía crítica elaborada en la segunda mitad del siglo XX impugna la identidad establecida por la cultura dominante, al considerarla un medio de interiorización de un sistema social opresivo y disciplinario que se introduce sutilmente en los cuerpos con el fin de reproducir las estructuras de poder establecidas. En ese sentido, pensadores tan destacados como Bataille, Lacan, Foucault, Deleuze, Guattari, Castoriadis, Marcuse, las ya citadas Irigaray o Butler, pero también Wittig o Shiva, son ejemplos de pensadores de distintas orientaciones que han dedicado gran parte de su trabajo a poner en cuestión el modo y los mecanismos que han construido la subjetividad en Occidente, siendo uno de sus objetivos primordiales idear mecanismos teóricos que permitan interferir en los procesos de asignación de identidades y pensar estrategias de creación de singularidades capaces de sustraerse de la serialización de los individuos, con el objetivo de constituir modos de percibir, pensar, hablar y actuar que puedan ser considerados verdaderamente autónomos. 
de la cultura occidental. La impugnación del paradigma de la homogeneidad requiere un tránsito teórico por el que se asuma la complejidad de los elementos que tejen las identidades, sus ramificaciones y bifurcaciones, sus transiciones y metamorfosis. Para la óptima proliferación de la diferencia conviene - haciendo uso de un concepto que utiliza habitualmente Braidotti y que recoge de Deleuze- devenir "singular" o "minoritario"; es decir, se hace necesario impulsar un trabajo de debilitamiento de la propia identidad, y de los atributos generales con los que se la normaliza, que abra la puerta a la potenciación de los niveles de intensidad y velocidad con el que se generan las conexiones que mezclan y ajustan, confunden y multiplican las posibilidades de expansión de las distintas entidades vivas. A este proceso es a lo que Braidotti refiere cuando habla de transposiciones, las cuales son los "desplazamientos creativos que engendran interconexiones de tipo no lineal" (2009: 244) donde la conducta humana no pretende imponer la propia individualidad, y con ello anticipar y controlarlo todo, sino desterritorializar, abrir espacios de movimiento fluidos donde el sujeto discontinuo (desigual a sí mismo, aunque no fragmentado) que ha renunciado ascéticamente a sí mismo (Braidotti 2009: 245) desarrolla su potencia humildemente, esto es sin dañarse a sí mismo ni a los otros — conforme al criterio de la sustentabilidad, que analizaremos posteriormente-. En último término, como se observa, lo que realmente importa y conviene resaltar es el intento por crear los mecanismos o estrategias teóricas que en la práctica dejen que la diferencia sea. En tal sentido, Braidotti propone como modos de transposición la posibilidad de devenir mujer, de devenir otro, animal, mundo o, incluso máquina, distintas reconfiguraciones de la subjetividad que aunque están por hacer, por venir, y por tanto por pensar y acontecer, remiten, nominativamente al menos, a modalidades de ser que han sido en la civilización occidental históricamente reprimidas o, en todo caso, situadas en una escala ontológica inferior al Hombre, el paradigma o referente sobre el que se ha edificado la cultura antropocentrista que impulsa en la actualidad el capitalismo neoliberal avanzado. De hecho, la promoción de unos valores postantropocéntricos tienen importantes repercusiones en el terreno de la crítica económica y en la ética, tal y como veremos posteriormente.

La posibilidad de devenir diferente, en Braidotti, converge con la reivindicación que diversos colectivos realizan y que pretenden modificar las condiciones existenciales, políticas y jurídicas, que se desprenden de su inadecuación respecto de la subjetividad dominante. El feminismo, el postcolonialismo, la lucha contra la xenofobia y el racismo, o la defensa del medio ambiente y de su biodiversidad, obtienen un fuerte apoyo teórico 
en la ética tal y como es planteada en su obra, pues se entiende, aunque a simple vista pueda parecer paradójico, que la única vía que hace posible alcanzar un trato equitativo e igualitario con la diversidad humana, biológica y medioambiental, es la asunción de la necesidad de defender y promover la heterogeneidad de las formas de vida. Dicho de un modo aún más claro: la manera más propicia para acercarse a la igualdad jurídico-política es a través del fomento y el respeto por la diferencia.

\section{La ética de la subjetividad nómade}

La ética de la diferencia positiva que plantea Rosi Braidotti defiende una concepción no unitaria, nómade y posthumana de la subjetividad, la cual encuentra su punto de apoyo en una ontología monista y materialista y que a su vez tiene su fundamento en la ontología del proceso que se desarrolló a lo largo del siglo XX, presentándose como una alternativa a la metafísica tradicional - al igual que otras propuestas críticas con la misma, tales como la hermenéutica o la deconstrucción, ambas de filiación heideggeriana- y que tiene como principales referentes a Whitehead, Bergson, Simondon y al ya citado Deleuze. Estos pensadores, más allá de sus diferencias y que por falta de espacio en este artículo nos es imposible abordar, tienen en común la oposición a la creencia según la cual la realidad puede ser definida apelando a categorías estables, si bien son igualmente críticos con la perspectiva que defiende que aunque la realidad cambia, tal proceso se define por una lógica lineal, causal y, en último término, racional, pues encarna el desarrollo de una idea. Según la filosofía del proceso, la realidad también se constituye y se despliega, aunque lo hace en el marco de un curso abierto e imprevisible, en el que es posible el acaecimiento de la diferencia.

Si el último Whitehead afirma que todas las cosas fluyen (1956), para Bergson (1973), la realidad se ofrece como perpetuo devenir, se hace o se deshace pero nunca es algo hecho; posición que comparten igualmente Simondon y Deleuze en sus ontologías. Es común asimismo a este grupo de pensadores la creencia en que el proceso de transformación que caracteriza el acontecer de lo real tiene un margen de indeterminación irreductible a cualquier lógica racional que permita anticiparlo o preverlo. La duración de la realidad, en Bergson, remite a la continuidad que existe entre los diversos procesos que articulan su devenir, pero teniendo en cuenta que este encierra la eventual aparición de lo nuevo, yendo más allá de la noción clásica de lo posible, que se entiende como una cualidad oculta que está a la espera de 
ser actualizada. La realidad, en Bergson, se constituye en cambio dado el acontecer de una potencia que transciende las puras posibilidades lógicas y que permite la aparición de la novedad, algo con lo que coincide Simondon en su explicación del proceso de individuación y que explica, en el contexto de su filosofía, de modo magistral Deleuze en su famosa distinción entre lo transcendental y lo empírico.

Braidotti continúa la senda abierta por los pensadores citados afirmando, por ejemplo, que "ve a los sujetos como modos de individuación dentro de un flujo común de zoé" (2009: 220). Con la noción de zoé, de vital importancia en su ontología, Braidotti refiere a la "vida misma", la cual es entendida como la potencia o energía vital productiva y creativa que da lugar a la proliferación inconmensurable de múltiples y heterogéneas existencias. A su continua transformación y dinamización. Zoé es vida que muta, que se expande y que prolifera: "una fuerza generadora inexorable" (Braidotti 2009: 363) que se autoorganiza. El ser humano forma parte de la riqueza productiva de zoé, estando conformado por la misma potencia intensiva que caracteriza a toda forma de vida. De acuerdo a ello, la subjetividad en tanto recoge el modo de ser propio del humano, ha de entenderse asimismo en su carácter procesual: en tanto que existencia, deviene. La subjetividad acontece, se da, no es (Braidotti 2004: 55). La subjetividad nómade, tal y como la define Braidotti, se sitúa por tanto en el eje de pensamiento que impugna la ontología tradicional, y su concepción sólida, unitaria y universalizante del sujeto propia del humanismo metafísico, ofreciendo una alternativa que está en consonancia con la ontología materialista del devenir a la que aludíamos. Y es que el interés o la necesidad de plantear un tipo de subjetividad ya no metafísica responde precisamente a la exigencia de superar los planteamientos esencialistas que esta trae consigo. Frente a la concepción tradicional del sujeto, propia del humanismo liberal, donde se entiende como una entidad racional y autoconsciente, internamente cohesionada y unida, cuya identidad va más allá de los procesos contextuales e históricos, libre para tomar decisiones y tomar el control respecto del resto de formas de vida - pues se sitúa en un lugar de privilegio respecto de estasel posestructuralismo en general, y Braidotti en particular, plantean la subjetividad como una compleja estructura multiestratificada donde la corporalidad sustituye a la conciencia como el lugar de reconocimiento y síntesis del sí-mismo, y que se encuentra atravesada por multitud de fuerzas y líneas energéticas que la tejen y destejen en un proceso continuo e interminable. Ser sujeto, para Braidotti, en primer lugar y sobre todo es ser cuerpo, una materia intensiva que está expuesta a multitud de fuerzas externas que la 
atraviesen y la moldean, otorgándole una estructura multiforme susceptible en todo momento de estar en vías de transformación, aunque tal proceso es imprevisible. En palabras de la propia Braidotti:

El cuerpo, o el incardinamiento del sujeto, no debe entenderse ni como una categoría biológica, ni como una categoría sociológica, sino más bien como un punto de superposición entre lo físico, lo simbólico y lo biológico (2004: 214).

En ese sentido, el contexto socio-cultural —donde lenguaje, saberes y técnicas juegan un papel esencial-y las reglas sociales, los valores culturales y las prácticas asociados a ellos, constituyen un entramado significativo que inscribe de infinidad de datos los cuerpos, tejiéndolos en distintos estratos intervinculados. La subjetividad, por tanto, se produce en red, como una composición colectiva que se altera con el contacto con los demás seres humanos. La subjetividad es una multitud, y se define por su interna alteridad.

Otra de las características que definen la subjetividad humana, en tanto se entiende como una entidad incardinada e incorporada —es decir, enraizada en el cuerpo-, es la relevancia que en ella posee la afectividad. Los afectos - las pasiones, las emociones y los sentimientos- pasan a ocupar un lugar de privilegio en el estudio del modo con que el sujeto construye tanto la imagen de sí mismo como del mundo que le rodea, completando y complementando a la racionalidad, la facultad que la filosofía tradicional había considerado como la más propia y específicamente humana. Una de las consecuencias más notables de ello, es precisamente la negación de la centralidad de la razón como el atributo más representativo de la misma. El ser humano, para Braidotti —en la línea abierta por Spinoza primero y por la lectura que de este hace Deleuze después- ya no es sólo razón, sino que esta pasa a entenderse como una herramienta de relación con el entorno inscrita en el espacio de expresión de la vida como acontecer, volviéndose ilícito abstraerla de su contexto con el fin de situarla como la cualidad en la que descansa la identidad y que permite conocer la realidad "tal y como esta es". De hecho, Braidotti entiende que se debe abandonar el paradigma racionalista para abordar otro más complejo y plural donde, por una parte, se asuma que el ser humano no coincide con su conciencia racional (2004: 66), dando paso a una visión de la subjetividad más inestable, contradictoria y elusiva que la versión metafísica, mientras que, por otra, se advierte de que la razón como facultad de conocimiento, no puede operar autónoma e independientemente tanto de los códigos semióticos con los que se articula, como de los procesos histórico-contextuales en que se inscribe. Ello acarrea 
necesariamente una revisión de la concepción y de las posibilidades de la ciencia, ya que la concepción purista de esta, la entiende como la realización de un estadio totalmente racional donde el ser humano describe de un modo neutro, objetivo y desideologizado lo real. Para Braidotti, esta perspectiva queda desmentida a favor de una idea más abierta y compleja de la investigación científica, que asuma que existen diversos elementos de contaminación exteriores que la condicionan y determinan. ${ }^{5}$ No obstante, ello no quiere decir que la razón deje de ser una facultad esencial para la comprensión significativa de la realidad, sin embargo, se deben dejar de lado las percepciones dogmáticas acerca de sus capacidades.

Plenamente consciente de los ataques realizados al posestructuralismo en tanto abriría la puerta al irracionalismo y a la dispersión esquizoide, la razón, para Braidotti, da lugar al flujo de conciencia, poseyendo una función sintética, de integración y auto-reconocimiento, ya que sincroniza espacio-temporalmente las experiencias, las vivencias, los pensamientos y los afectos, siendo por lo tanto esencial para la conformación de la subjetividad. En ello, la memoria juega igualmente un papel esencial (2009: 210). La subjetividad dura, soporta los cambios y las transformaciones sustentables, aunque sin ser entendida como una esencia que permanece incólume atada y replegada sobre sí misma, tal y como ha sostenido la tradición metafísica occidental. A pesar de que la razón deja de interpretarse como la facultad donde se localiza la esencia más íntima de la identidad, es imprescindible para dotar de unidad y consistencia al sujeto (2009: 211).

Otro efecto destacable de la reducción de la centralidad de la razón en beneficio de los afectos, es la crítica a la idea, muy arraigada en la mentalidad dominante, según la cual el pensamiento o la racionalidad son atributos superiores que entre sus diversas funciones poseen la de ejercer control sobre el mundo de los afectos, y de la irracionalidad y arbitrariedad que estos suponen. En el paradigma racionalista, la mesura, la prudencia, la moderación e, incluso, la sensatez y la cordura, provendrían exclusivamente de la influencia de la razón sobre la emotividad, que sería impulsiva, descontrolada y exaltada por naturaleza, cualidades que suelen tener como consecuencia que el ser humano yerre, se extravíe o directamente se corrompa y se pierda a sí mismo en la peor de las depravaciones. La razón,

5 Según Braidotti, todo proceso cognitivo o de pensamiento se encuentra localizado, es decir está situado en un contexto específico en el que funcionan múltiples variables. No existe, entonces, una teoría abstracta, universal u objetiva, que explique de un modo neutro un determinado aspecto de la realidad (2004: 15). 
en este sentido, es la facultad que posibilita la toma de buenas decisiones encauzando la conducta hacia la normalidad, hacia lo que se espera de ella: el decoro y las buenas maneras. No es baladí, por otra parte, que históricamente, en nuestra civilización, se haya vinculado al hombre con la racionalidad y a la mujer con las pasiones, dejando en evidencia qué género debe ejercer autoridad sobre el otro. ${ }^{6}$ La disolución del logocentrismo occidental, que Braidotti propone - alineándose y continuando con la tradición deconstructivista y postestructural - posee una fuerte carga liberadora muy útil para las reivindicaciones feministas, la cual se puede añadir a las luchas de otros grupos sociales históricamente segregados: los bárbaros, los extranjeros, los no-blancos, los ignorantes o directamente los pobres, los cuales también fueron privados de la facultad de la razón. Con el fin de erradicar las discriminaciones y los prejuicios de los que fueron objeto los grupos sociales citados, no sólo se vuelve imprescindible atribuirles a todos ellos la facultad racional, sino igualmente devolverle la dignidad perdida al mundo de los afectos y las emociones, ya que en su aplicación o ejercicio reside más claramente que en la propia razón la capacidad para vincular de un modo empático y pacífico a las culturas, grupos sociales o colectivos que difieren del canon dominante. Y es que para Braidotti, ser una entidad afectiva implica sentirse conectado con todo lo que existe; comprender tal interdependencia es esencial no sólo para el desarrollo de la propia subjetividad sino para el propio acontecer de la vida ética. Por ello, sostiene que la subjetividad es reticular, pluralmente modelada, en tanto no puede comprenderse sin su relación codependiente con las otras subjetividades. El sujeto está interconectado y para comprenderse debe mirar tanto a su interior como a la malla de relaciones en las que se encuentra situado activa y pasivamente; en ese sentido la vida, la cual cabalmente posee una acentuada raíz ética, consiste en "afectar y ser afectado" (Braidotti 2009: 179). En ser consciente de que la efectuación de la existencia solo posee sentido en la medida en que abre planos de relación que estaban ocultos o se encontraban obstruidos. La vida ética consiste, por tanto, en la praxis que permite desbloquear los flujos por donde transitan las posibilidades de apertura a lo no acontecido, aquellos que permiten la superación de la repetición o de la

${ }^{6}$ Del mismo modo ocurre en la definición de democracia. La más habitual crítica a la democracia radical o participativa señala que es el modo de gobierno en que la masa, la turba, que no es sino el pueblo guiado por las pasiones, toma el control sobre la política adoptando decisiones en su mayoría erróneas. La política de altura se ejerce cuando la razón recupera el gobierno, la cual curiosamente ocurre cuando un reducido grupo de personas —sabias - toma las decisiones a costa de los demás (Rancière, 2006). 
homogeneidad y que pretende que todo permanezca igual: quieto, inactivo, inmóvil y depotenciado.

En la medida en que el devenir de la subjetividad depende del contacto y de la interacción con los otros, del ser afectado por la alteridad, debe dejarse de lado otro de los atributos con los que era interpretada en el contexto de la metafísica moderna: su individualidad, su no-división e integridad. Al aceptarse que el ser humano está dividido, siendo fruto de múltiples líneas de influencia que dependen de variables múltiples que se sitúan tanto en un nivel sincrónico como diacrónico, al asumirse que deviene y que es procesual, debe aceptarse a la vez la interna alteridad que lo conforma. La individualidad estalla entonces en un crisol de modalidades y códigos de relación y comunicación, entretejida por una diversidad que la hace irreductible a la imagen de integración y repliegue sobre sí misma que dibuja, por ejemplo, el individualismo liberal. Efectivamente, la propuesta de Braidotti, en coherencia con lo señalado, rechaza los valores que se desprenden de aquel: la competencia, la rivalidad, el permanente desafío y lucha por ser el mejor —el más competente, el más productivo, el más rentable ${ }^{7}$, la codicia y la avaricia por poseer, precisamente aquello que los otros no tienen -y que inducen un estado permanente de frustración incolmable-, son valores propios de alguien cuya concepción de sí reside en la creencia en que la subjetividad es una entidad separada y aislada del contexto social que la rodea, como si fuera depositaria de un conjunto de elementos propios inalienables que la identifican y la separan de las demás. Frente a la ética del aislamiento liberal, Braidotti entiende, en cambio, que se debe idear y difundir otra que se preocupe por, dicho con sus propias palabras,

comprender que compartimos una naturaleza común con otros y, al mismo tiempo, conservar la preocupación por los individuos que nos rodean y, por eso mismo, ser capaces de trascender nuestro interés personal preocupándonos por nuestros semejantes (2009: 228).

Preocupación que se concreta en una forma de entender las relaciones sociales de un modo mucho menos competitivo y por ello menos agresivo o violento, lo cual permite articular una ética alternativa a la de raíz liberal, que se concreta en una serie de principios básicos tales como los siguientes:

los criterios indicados por esta nueva ética incluyen: el principio de no-profit; el énfasis en lo colectivo; la aceptación de la relacionalidad y las contaminaciones virales; los intentos concertados para experimentar y concretar opciones virtuales y poten-

7 “[...] el individualismo genera egoísmo y egocentrismo, la autodeterminación puede transformarse en arrogancia y dominación” (Braidotti 2015: 43). 
ciales; la nueva conexión entre teoría y práctica; y el papel central de la creatividad (Braidotti 2015: 226).

Entre los aspectos señalados, y como se puede observar en la última frase del fragmento seleccionado, el sujeto nómade que propone Braidotti tiene entre sus atributos u objetivos la potenciación de la innovación, aspecto que no debe ser interpretado desde una perspectiva técnica o instrumental, sino más bien desde un punto de vista ontológico: el ser nómade implica promover la búsqueda de los mecanismos que permitan mutar, variar o, incluso, devenir otro. La creatividad remite a la afirmación de sí a través de la integración de la diferencia, asumiendo la proliferación y multiplicación tanto de la identidad propia como de la ajena. Una vida ética supone afectar y ser afectado. En este sentido, la propuesta de Braidotti es semejante a la concepción del Übermensch nietzscheano, al menos tal y como lo interpreta Gianni Vattimo, quien lo concibe como un artista que se relaciona con el mundo experimentándolo y donde él mismo es un experimento que se pone en juego (Vattimo, 39). El Übermensch, y también la subjetividad nómade, procuran elevar sus capacidades hasta el umbral máximo posible. En relación a ello, conviene no olvidar, como decíamos, que la afectividad es un componente fundamental para el devenir de la subjetividad, en tanto a través de ella se pone en liza el deseo como potencia. Y es que quizá el rasgo que más destaque y en el que haya que poner mayor énfasis en lo tocante a la importancia que posee la afectividad en la comprensión de la subjetividad humana en Braidotti en concreto, pero también en el postestructuralismo de filiación deleuziana, es precisamente que a través de ella se manifiesta el deseo como potencia. El impulso vital o la energía intensiva que pone en acción el movimiento imparable, heterogéneo y divergente que late en toda vida. Tal potencia, interpretada en su más pura positividad, escapa al dominio que pueda ejercer sobre ella un sujeto racional o inteligente; más bien, la concreción de tal potencia es la que da lugar y permite la aparición de formas inteligentes de vida. Se entiende así que el conatus y el deseo se interpreten como formas que están más allá de lo humano, siendo compartidos por toda forma de vida ya que remiten a zoé, a la naturaleza en tanto dadora de vida, donde esta brota y deviene.

De acuerdo a lo dicho, conviene resaltar que la subjetividad humana está marcada profundamente por el deseo como potencia, como energía positiva que aparece y se ejerce, generando multitud de conexiones y ejes de intersección relacionales, los cuales se van imprimiendo y codificando en una materia. Como dice Braidotti, 
El sujeto es una entidad afectiva, un conatus definido como un «esfuerzo» $\sin$ un agente que lo controle. Este deseo fundador es una fuerza vital que se interseca con todo lo que se mueve y existe. Lejos de poseer o controlar dicha fuerza, el sujeto lo es al compartir tal esfuerzo (2009: 222).

En coherencia con lo señalado, uno de los criterios de elección que articulan la ética de la diferencia nómade, consiste en la localización de aquellas prácticas que permiten que la diferencia prolifere, que aumente la potencia, que la subjetividad desarrolle toda su fortaleza, y que sea capaz de movilizar todas sus capacidades. Ahora bien, es posible plantearse las siguientes cuestiones, este vigor energético ¿hasta donde cabe extenderlo? ¿Acaso una apuesta tan radical por la positividad no puede acabar por convertirse en una amenaza para uno mismo y para los otros? ¿Acaso una positividad tan extrema no puede concluir en vez de en la defensa de la proliferación de la diferencia, en su negación y rechazo, en su silenciamiento a través del ejercicio de la violencia? ¿No es posible que un deseo irrefrenable y sin barreras oculte en sí mismo el germen de la violencia y de la pulsión de destrucción? Dicho de otro modo, y por concretarlo en una pregunta específica ¿hasta dónde cabe elevar la potencia? Dado el reconocimiento de tales peligros, Braidotti completa la ética de la diferencia positiva con una de la sustentabilidad, la cual tiene como un principio básico la asunción de la necesidad de plantear y encontrar la existencia de límites que sirvan como el criterio de referencia para no caer en el exceso destructivo. En la exageración, el abuso, el extremismo y, en definitiva, en la violencia. La ética de la sustentabilidad se edifica sobre la conciencia de la existencia de umbrales que marcan la pauta que hace posible bordear el abismo sin desaparecer en él, teniendo como función impedir el llevar más allá de lo soportable o de lo admisible la realización de la potencia.

En el capítulo V de Transposiciones se define la ética precisamente como "el modo de realizar formas sustentables de transformación que requieren de uniones e interacciones adecuadas" (2009: 296), siendo entendidas estas, las adecuadas, como aquellas que favorecen el aumento de devenires activos, evitando los que disminuyen la potencia, algo que sucede cuando se sobrevalora lo individual y el cálculo egoísta y se deja atrás la afinidad y la empatía por otras formas de vida. No obstante, Braidotti no intenta especificar de un modo objetivo dónde se encuentra lo sustentable, ya que este ni es exacto ni es susceptible de medida, sino que remite a lo que los cuerpos sean capaces de hacer o puedan resistir, lo cual depende de factores de tipo biológico, físico, psíquico, histórico y sexual; lo sustentable es singular y parcial (2009: 297). Por tanto, uno de los elementos básicos de la ética de 
la diferencia refiere al reconocimiento de los propios límites y al respeto por los ajenos, teniendo en cuenta que no son estables ni inmutables, ni existe un criterio objetivo que permita fijarlos de una vez por todas.

[...] el punto de partida no es el individuo aislado, sino las correlaciones complejas y mutuamente dependientes, la interacción sí mismo/otro también sigue un modelo diferente. Ser un individuo significa estar abierto a la posibilidad de ser afectado por otros y a través de otros y de experimentar transformaciones de un modo que me haga capaz de sustentarlas y de volverlas a favor del propio crecimiento (2009: 225).

En tal sentido, la ética de la sustentabilidad se complementa con una lógica de la humildad que permita trazar un mapa de las relaciones personales, donde se asume que el desarrollo de la potencia debe ser compatible con la elusión del daño a uno mismo y a los demás, evitando, a la vez el ser dañado por los otros. Con este fin Braidotti retoma de Deleuze una suerte de neoascetismo, vinculado al hecho de "devenir imperceptible", que "defiende una renuncia ascética del sí mismo, de la muy querida pero en última instancia limitada identidad propia y la apertura del aparato perceptivo a un complejo de múltiples conexiones, sensaciones, percepciones e imaginaciones" (2009: 245) que permiten desde un cierto abandono de sí mismo —una suerte de "impersonalidad ascética" (2009: 247) — el encuentro y la apertura con la diferencia, aplicando las virtudes éticas de la compasión, de la afinidad intensa y de la responsabilidad, tanto con una comunidad o un pueblo, como con un territorio. Y es que la ética de la sustentabilidad se completa con una atención especial por los ecosistemas, poseyendo, en Braidotti, una clara vocación ecológica.

La cuestión medioambiental, a pesar de que se bosqueja en Transposiciones ocupa un lugar central en Lo posthumano, texto en el que se sientan las bases de una teoría postantropocéntrica que hace posible, por una parte, desalojar al ser humano del lugar de preeminencia en que lo había situado el humanismo clásico, a la vez que alerta del papel fundamental que posee para la lucha por la conservación del planeta (Braidotti 2015: 104). Para Braidotti, en el contexto de la sociedad altamente tecnificada contemporánea, en la que el ser humano a través de la ciencia y de su aplicación tecnológica parece tener un control completo de los procesos naturales, y donde aparenta llevarse a cumplimiento el sueño humanista por el que el ser humano es capaz de elevarse más allá de las leyes inexorables de la naturaleza, sometiéndola y dominándola conforme a sus propios intereses, se abre la posibilidad precisamente al proceso contrario a este: a la disolución del humanismo y de sus ansias de control y poder. La misma dinámica el "progreso" y el "avance" científico-tecnológico- que parece evidenciar 
la autoridad de la especie humana sobre el resto de formas de vida, debe conducir a la reducción del poder hegemónico del ser humano tanto sobre la tierra como sobre la biosfera. Es el proceso de metamorfosis - no teleológico- en el que se halla embarcado el ser humano en tanto que especie - donde naturaleza y cultura se conjugan, de hecho Braidotti habla de un continuum naturaleza-cultura- el que conduce a una etapa posthumana y postantropocéntrica por venir.

\section{4. Ética posthumana}

En el último de los libros publicados por Braidotti, Lo posthumano, se profundiza en varios de los aspectos ya tratados en obras anteriores. De hecho, en Transposiciones hay un apartado titulado precisamente "El posthumanismo" (2009: 55-60) donde se reclama la necesidad de construir un discurso que vaya más allá de los postulados humanistas y que inscriba a la humanidad en un marco más amplio, donde es la vida en general, y no únicamente la vida humana, la que funciona como el punto de referencia sobre el que anclar los valores éticos sustentables. Para llevar a cabo este proyecto, se debe profundizar en la senda abierta por la noción de subjetividad nómade y las consecuencias éticas que trae aparejada, siendo el posthumanismo la línea de pensamiento que denuncia al humanismo autocomplaciente, y el acentuado antropocentrismo eurocéntrico, universalista y teleológico que supone, y que entiende a lo Otro como una contraparte negativa y especular de la auténtica humanidad. En cambio, el posthumanismo como distorsión de tal planteamiento, asume la positividad de la diferencia, comprometiéndose con posiciones feministas, poscoloniales, antirracistas y ecológicas, esas que en su inscripción dotan de voz a aquellos que fueron excluidos y silenciados por entenderse como "menos humanos": las mujeres, los "bárbaros" o las especies vivas no humanas. Para ir "más allá del humanismo" se debe encontrar un nuevo modo de entender la "humanidad". La subjetividad nómade tal y como la concibe Braidotti, y tal y como la hemos explicado, da respuesta a tal intento, impugnando el esencialismo sustancialista metafísico y defendiendo la necesidad de instaurar un sujeto procesual, des-sujetado, vital, encarnado, incardinado en unos lugares precisos, pero a la vez relacional y múltiple. El posthumano, como actualización de la subjetividad nómade, refiere precisamente a la nueva identidad postnacionalista, cosmopolita y panhumana, que acontece en la actualidad dados los nuevos avances tecnocientíficos capaces de modificar 
los atributos anatómicos y fisiológicos que hasta la fecha han definido a la humanidad.

La posthumanidad acaece en el contexto de desarrollo de las ciencias más avanzadas, como la biogenética, la biología molecular, la robótica, la informática o la primatología, recogiendo también la influencia del desarrollo y extensión de las redes digitales de información y de los medios de comunicación que, dicho todo lo sintéticamente que se puede, tienen como consecuencia en su aplicación, la transformación del ser humano, haciéndolo mutar en una combinación de organismo y mecanismo artificial y digital: un cyborg (Haraway, 1991), es decir, un nuevo tipo de entidad viva y de la que es difícil predecir sus cualidades futuras, pero en la que las mejoras genéticas, los implantes nanotecnológicos o la relación de la conexión entre mente humana y red electrónica, jugarán un papel esencial. La posthumanidad, supone por tanto el devenir máquina, el acontecer de un estado incipiente donde la subjetividad cibernética quiebra la distinción entre ser humano y circuitos tecnológicos (Braidotti 2015: 84), convirtiendo al humano en un cuerpo biomediado que posee otra percepción y otra representación del mundo radicalmente distinta de la actual.

No obstante, el postantropocentrismo posthumano, que pone en crisis la noción tradicional de anthropos, da pie a su vez a una reconsideración de la relación que guarda con las demás formas de vida, cuestionándose el lugar central en que aquel lo situara, para abrirse a un zoecentrismo donde el respeto por la vida pasa a ser el postulado ontoético de referencia. Braidotti lo explica perfectamente cuando sostiene:

[...] si la decadencia del humanismo inaugura lo posthumano exhortando a los humanos sexualizados y racializados a emanciparse de la relación dialéctica esclavoamo, la crisis del anthropos allana el camino a la irrupción de las fuerzas demoníacas de los otros naturalizados. Animales, insectos, plantas y medio ambiente, incluso planeta y cosmos en su conjunto son llamados a juego. Esto pone otra carga de responsabilidad sobre nuestra especie, que es la causa principal del desastre ecológico. [...] La teoría nómada posthumana impugna la arrogancia del antropocentrismo y el excepcionalismo de lo humano en cuanto categoría trascendental (2015: 83).

En la posthumanidad el ser humano ya no se sitúa por encima de la tierra y del resto de especies vivas, sino en una posición de igualdad respecto a ellas, siendo los niveles de autoconciencia alcanzados los que le inducen al desarrollo de una ética de la responsabilidad que se ejemplifica en el cuidado y la promoción de la diferencia, ya no humana sino medioambiental. En consecuencia, el devenir máquina se completa con un devenir animal y un devenir tierra, que tienen como ejes de transformación respectivamente la 
solidaridad transespecie —en tanto el ser humano es un animal más, arraigado como cualquier otro al ecosistema- y el cuidado y la preocupación por el mantenimiento de la sostenibilidad del mismo (Braidotii 2015: 84), comprometiéndose con las estructuras político-económicas que impiden su paulatino aniquilamiento y destrucción. Por ello, la ética posthumana se enfrenta tanto al neoliberalismo globalizado - por ser el sistema económico que sobreexplota los recursos materiales y energéticos, que agrede la biosfera contaminándola y convirtiéndola en un vertedero donde depositar los residuos industriales, que propicia un aumento de temperatura en el planeta de consecuencias incalculables, y que además entiende a las distintas formas de vida solamente desde criterios económicos, no dudando en colonizar espacios naturales reduciéndolos a mercancías con los que obtener mayor rentabilidad económica- como al liberalismo individualista — que es el sistema ético asociado al neoliberalismo, y que produce un tipo de ser humano egocéntrico y egoísta cuyo estilo de vida se basa en la producción y el consumo ilimitado de objetos-.

La lógica neoliberal ha de ser superada, siendo la propuesta posthumana una vía alternativa sugestiva para reparar o reducir sus problemas más manifiestos. Según Braidotti,

el igualitarismo zoe-centrado es el núcleo de inflexión postantropocéntrica: es una respuesta materialista, laica, fundada y concreta a la oportunista mercantilización transpecie que es la lógica del capitalismo avanzado (2015: 77).

Mientras el capitalismo transforma la vida en un bien de consumo, Braidotti propone defenderla como fuente de experimentaciones intensivas gratuitas. El posthumano se convierte así en una suerte de nuevo sujeto de una era postcapitalista porvenir, que al hacerse consciente de que su identidad se inscribe en un espacio de vida que no controla ni posee, se reconoce en una ética de la positividad intensiva capaz de abrir flujos y líneas de tránsito ante el bloqueo del deseo que plantea la lógica capitalista. El sujeto posthumano, por tanto y en definitiva, una vez que se deshace de las ataduras tradicionales, se encuentra en disposición de liberar los flujos de afectividad que permiten construir espacios solidarios, respetables y sustentables donde se encuentren y convivan las diferentes formas de vida. 


\section{Bibliografía}

Bergson, H., La evolución creadora, Madrid, Espasa Calpe, 1973.

Braidotti, R., Sujetos nómades. Corporización y diferencia sexual en la teoría feminista contemporánea, Buenos Aires, Paidós, 2000.

Braidotti, R., Feminismo, diferencia sexual y subjetividad nómade. Barcelona, Gedisa, 2004.

Braidotti, R., Metamorfosis, Madrid, Akal, 2005.

Braidotti, R., Transposiciones, Barcelona, Gedisa, 2009.

Braidotti, R., Lo posthumano, Barcelona, Gedisa, 2015.

Cardenal Orta, T., "La "extraña dentro": El feminismo nómada de Rosi Braidotti”, Universidad de Zaragoza, Facultad de Filosofía y Letras, 2012. Consultado en https://zaguan.unizar.es/record/9242/files/TAZTFG-2012-695.pdf, fecha 05/10/2017

Deleuze, G., Diferencia y repetición, Madrid, Amorrortu, 2002.

Femenías, M.L. y Ruiz, M., "Rosi Braidotti: de la diferencia sexual a la condición nómade". Revista de Historia, Argentina, Vol. 1, n 3, 2004. Consultado en http://redalyc.uaemex.mx/pdf/638/63810305.pdf, fecha: 03/09/2017

Haraway, D., Ciencia, cyborgs y mujeres, Madrid, Cátedra, 1995.

Rancière, J., El odio a la democracia, Buenos Aires, Amorrortu, 2006.

Simondon, G., La individuación a la luz de las nociones de forma y de información. Buenos Aires, Cactus, 2015.

Vattimo, G., Más allá del sujeto, Barcelona, Paidós, 1992.

Whitehead, A.N., Proceso y realidad. Buenos Aires, Losada, 1956. 